\title{
Immaterial boys? A large-scale exploration of gender-based differences in child sexual exploitation service users
}

Authors: Ella Cockbain, Matthew Ashby and Helen Brayley

Published: Sexual Abuse: A Journal of Research and Treatment, December 2015

Published, formatted version available at:

http://sax.sagepub.com/content/early/2015/12/02/1079063215616817.abstract

\section{Abstract}

Child sexual exploitation is increasingly recognised nationally and internationally as a pressing child protection, crime prevention and public health issue. In the UK, for example, a recent series of highprofile cases has fuelled pressure on policy-makers and practitioners to improve responses. Yet, prevailing discourse, research and interventions around child sexual exploitation have focused overwhelmingly on female victims. This study was designed to help redress fundamental knowledge gaps around boys affected by sexual exploitation. This was achieved through rigorous quantitative analysis of individual-level data for 9,042 users of child sexual exploitation services in the UK. One third of the sample was male and gender was associated with statistically significant differences on many variables. The results of this exploratory study highlight the need for further targeted research and more nuanced and inclusive counter-strategies.

\section{Key words}

Child sexual exploitation; child sexual abuse; victims; gender; sexual offences 


\section{Introduction}

Once routinely dismissed as consensual child prostitution, child sexual exploitation (hereafter CSE) is increasingly recognised as a serious child protection and crime prevention concern (e.g., Barrett and Melrose, 2003; Barnardo's, 2012; Chase and Statham, 2005). Demands are growing for improved responses to CSE both nationally and internationally (see, e.g., Appleton, 2014; Home Affairs Select Committee, 2013). In the UK in particular, a key catalyst for such demands has been intense media scrutiny of recent cases involving large groups of offenders and revelations of historic CSE involving celebrities and politicians. Police and local authorities have been heavily criticised for failing to identify and respond adequately to CSE (e.g., Harvey, Hornsby \& Sattar, 2015; Jago et al., 2011; Jay, 2014). CSE's ascent up the political agenda has been accompanied by the publication of numerous national and local reports, guidance and action plans (e.g., ACPO, 2012; CEOP, 2011; CPS, 2013; DfE, 2011; Home Affairs Select Committee, 2013; Home Office, 2011, 2015; OCCE, 2012).

Before continuing, the term CSE itself merits discussion. CSE is often characterised as a distinct subset of child sexual abuse (e.g. Jago et al., 2011; Jago and Pearce, 2008). There is no international consensus around what constitutes CSE and even nationally accepted definitions can fail to delineate CSE from other from other forms of child sexual abuse (Brayley and Cockbain, 2014; Cockbain, 2013). CSE is not a distinct criminal offence in the UK. In the absence of a legal definition, professionals typically work to the definition found in government safeguarding guidance (e.g., DCSF, 2009; Welsh Assembly Government, 2010). Central to this definition is the concept of exchange, in that CSE is said to involve:

...exploitative situations, contexts and relationships where young people (or a third person or persons) receive 'something' (e.g. food, accommodation, drugs, alcohol, cigarettes, 
affection, gifts, money) as a result of them performing, and/or another or others performing on them, sexual activities.

(DCSF, 2009, p.9).

While the inclusivity of this definition may well be beneficial in promoting awareness and maximum possible identification of victims, it becomes problematic when used in scientific enquiry. The inclusion of intangible commodities such as affection in the above-cited definition means that - in the UK at least - virtually any form of child sexual abuse might qualify as CSE (Brayley and Cockbain, 2014). In practice, our experience has been that the term is normally applied in the UK to refer to extra-familial abuse of older children. This problematic discrepancy between the broad inclusivity of the formal definition and the narrower way in which it seems to be operationalised is rarely addressed in research or policy around CSE (see Cockbain, 2013). Instead, the term tends to be applied uncritically and without further explanation (exceptions include CPS, 2013). In the current study, we used secondary data about thousands of children who had been identified as requiring support in relation to CSE and subsequently received such services. It is important to be aware of the potential for inconsistent interpretation and application of the term CSE in the process by which our research data were originally generated.

Returning to the literature on child sexual abuse, it is well established that males constitute a minority of victims (e.g., Cashmore and Shackel, 2014; Finkelhor, 1994; Priebe and Svedin, 2009; Stoltenborgh et al., 2011). Diverse epidemiological studies into prevalence rates and other studies limited to pre-identified groups of victims have respectively concluded that males are at less risk of abuse than females and that they are in the minority among identified victims' (for a review see, e.g., Brayley, Cockbain \& Gibson, 2014; Cashmore and Shackel, 2014; Stoltenborgh et al., 2011). The 
marked variation between studies in terms of the relative risk to and/or representation of males as compared to females is often attributed to conceptual, definitional and methodological differences and to variations in the geographical and socio-cultural context of the research (Cashmore and Shackel, 2014; Paolucci, Genuis \& Violato, 2001; Stoltenborgh et al., 2011). In a seminal review of the child sexual abuse literature in 21 countries, Finkelhor (1994) reported prevalence rates ranging from $7-36 \%$ for females and 3-29\% for males. In most of the studies included, female-to-male ratios fell between 1.5:1 and 3:1. In a more recent meta-analysis of child sexual abuse prevalence globally, Stoltenborgh et al. (2011) reported European prevalence rates of $13.5 \%$ for females and $5.6 \%$ for males. While prevalence rates varied by continent (ranging from $11.3-21.5 \%$ for females and 4.119.3\% for males), they were higher (generally markedly so) for females than males in every continent bar South America. In a recent interview-based study with a UK-wide random probability sample of 2,275 11 to 17 year-olds, Radford et al. (2011) found that self-reported lifetime contact sexual abuse victimisation rates were 2.7 times higher among female respondents $(7.0 \%)$ than males (2.6\%). Reliable figures on the scale and prevalence of CSE in particular (as opposed to child sexual abuse in general) simply do not exist at present in the UK - disaggregated by gender or not (Cockbain, 2013).

Given the predominance of female victims and male offenders (see, e.g., Smallbone, Marshall \& Wortley, 2008), it is perhaps not surprising that much of the knowledge on child sexual abuse literature is filtered 'through the prism of victim as female and perpetrator as male' (Cashmore and Shackel, 2014: 75). Recent years have seen a gradual expansion of the literature on male victims of child sexual abuse in general (see, e.g., Alaggia, 2005; Cashmore and Shackel, 2014; Edelson, 2012; Homma et al., 2012; Priebe and Svedin, 2009; Scrandis and Watt, 2014). Nonetheless, in a recent rapid evidence assessment around child sexual abuse/exploitation, most of the 184 studies covered were found to focus exclusively or overwhelmingly on female victims (Brayley, Cockbain \& Gibson, 
2014). Even where victim samples included males, their characteristics, experiences and responses to them were rarely assessed independently of their female counterparts. With some notable exceptions (e.g. Priebe and Svedin, 2009; Smallbone and Wortley, 2000), larger analyses of child sexual abuse that have factored in gender as a variable have typically focused on primarily on its relationship to victimisation risk or the consequences of abuse (e.g. Paolucci, Genuis \& Violato, 2010; Stoltenborgh et al., 2011). As Cashmore and Shackel (2014: 76) note, 'there is limited research that specifically compares the experiences of male and female victims'. As a result, considerable knowledge gaps persist in respect to the interplay between victim gender and their individual characteristics, the abuse process and official responses to them. This is true for child sexual abuse in general but even more so for CSE, for which the research literature remains particularly underdeveloped (Brayley, Cockbain \& Gibson, 2014).

Recent targeted studies into CSE in the UK have aggregated the genders when examining the characteristics of the victim samples and of their exploitation (e.g., CEOP, 2011; OCCE, 2012). Given that boys have comprised a minority of victims in these studies (11-13\%), aggregation risks obscuring important differences between the males and females in the samples (Brayley, Cockbain \& Gibson, 2014). Looking again to findings from the literature on child sexual abuse as a broader category, there are grounds to believe that CSE involving male victims may differ systematically from that involving female victims (Brayley, Cockbain \& Gibson, 2014; see also Cashmore and Shackel, 2014). Studies have found that boys, in direct contrast to girls, are more likely to be sexually abused in an extra-familial than intra-familial context (e.g., Feiring, Taska \& Lewis, 1999; Moody, 1999; Smallbone and Wortley, 2000). A higher, albeit still typically low, proportion of boys than girls are sexually abused by females (e.g., Finkelhor, 1986; Nelson and Oliver, 1998). An analogous issue is the growing body of research on female child sex offenders that has shown them to differ from their male counterparts in certain key respects (for a review see Grayston and De Luca, 1999). 
There are evidently empirical and theoretical reasons why victim gender could be an important factor to consider in understanding and responding to CSE. Yet, in the UK and elsewhere, little has changed since Lillywhite and Skidmore (2006: 352) highlighted the 'persistent invisibility of boys and young men' in public, political, practitioner and academic discourse around CSE. Amid the shifting landscape around CSE in the UK, one constant is the tendency to conceptualise the phenomenon as something perpetrated by males against females (see, e.g., Cockbain, 2013). Several recent national reports and scoping studies have emphasised the paucity of research evidence around the sexual exploitation of boys and called for more targeted research on this topic (e.g., CEOP, 2011; DfE, 2011; Public Petitions Committee, 2014).

The majority of current service provisions in the UK are 'targeted towards young women rather than young men' (Lowe and Pearce, 2006: 289), meaning that male victims' needs may be overlooked and under-served. It has also been suggested that CSE detection and disclosure rates are lower for boys than girls (Lillywhite and Skidmore, 2006), meaning that the true scale of male-victim CSE may be even more underrepresented in official data than that of female-victim CSE. While insufficient robust research evidence exists to either support or to refute this claim, various reasons have been posited for why it might be the case. Alongside inadequate service-provision, common examples include the additional stigma associated with male sexual victimisation, fear of homophobia, femalecentric risk assessment tools and limited awareness among professionals that boys can be sexually exploited (Forrest, 2007; Lillywhite and Skidmore, 2006; McNaughton-Nicholls, Harvey \& Paskell, 2014; Palmer, 2001). Such issues are, it should be noted, also well-documented in respect to barriers to disclosing child sexual abuse in general (see, e.g., Homma et al., 2012). 
Amid this context, we designed the research presented here as a large-scale empirical assessment of the relationship between CSE and the gender of those children it affects. CSE is a sensitive and emotionally-charged issue and those affected by it are generally seen as a vulnerable and hard-toaccess research population (Palmer, 2001). Taking an unobtrusive approach to data collection, we were able to capitalise on an unusually extensive and detailed dataset spanning many thousands of CSE service users. As well as being among the first in-depth comparative analyses of gender and CSE (as opposed to child sexual abuse in general), our study is unusual in its large sample size.

Consequently, the findings are expected to have wider international relevance beyond the UK alone in informing the future research, policy and practice around CSE.

\section{Data}

Our dataset derived from the national database of service users held by Barnardo's, a nongovernmental organisation and the UK's largest provider of CSE services. In the absence of a centralised national recording system for CSE, the Barnardo's database (a centralised electronic case management system) is the single largest source of individual-level data about CSE in the UK. In the UK, it is common for specialist support services for issues such as CSE to be provided by nongovernmental organisations such as Barnardo's. Such services may receive directed funding from the government. Of course, access to such specialist services does not preclude more general involvement of statutory agencies in children's welfare (e.g., via social workers or safeguarding teams).

We were provided with raw data extracted from the Barnardo's anonymised central database of service users on $1^{\text {st }}$ November 2013. The full database includes information on service users supported for numerous issues other than CSE. To identify relevant individuals for our study, 
therefore, our data providers used the tag 'CSE' as a filter. This is a standardised tag used by all Barnardo's services to highlight when a case involves sexual exploitation.

We cleaned the dataset to remove duplicates and then went on to exclude a further 2,125 unique individuals that failed to meet our inclusion criteria (see Table 1). Our final sample consisted of 9,042 unique CSE service users (hereafter referred to as cases): 6,056 females and 2,986 males from 28 different services across England, Scotland and Northern Irelandi. The constraints of the original data limited us to examining differences between males and females, although we recognise that gender is a broader construct than the traditional male/female dichotomy alone.

Table 1 here

Except for the excluded cases previously mentioned, our sample represents all children supported by Barnardo's because of CSE between $1^{\text {st }}$ April 2004 and $1^{\text {st }}$ November 2013. We deliberately refer to this group as 'service users' or children 'affected by CSE' rather than 'victims'. The reason is that our sample included not only sexually exploited children but children implicated in sexually exploiting other children (peer-on-peer CSE) and those at risk of either (or both) of these conditions. Our focusgroup participants described the threshold for being deemed 'at risk' as quite high. They also stressed that referrals are based on a holistic assessment of individual children's circumstances, rather than the presence of any given demographic factor associated with risk. The breadth of the experiences covered in the sample is an asset as we were able to assess CSE in its entirety. Nonetheless, we recognise that the original data's failure to distinguish which category/categories ${ }^{i i i}$ each child fell into is a limitation of the study. 
While Barnardo's services work to a standard definition of CSE (DCSF, 2009), services may vary in their capacity and criteria for accepting a referral, mainly due to different funding arrangements. Additionally, the services do not cover the whole of the UK but rather certain geographical areas only. As such, it is possible that a child living in one area of the country would be referred to a CSE service (and therefore be recorded in the database) while a child in the same circumstances living elsewhere would not be captured in this particular dataset, either because there was no Barnardo's CSE service in that area or because the local service had different acceptance criteria.

In shaping our analysis, we were constrained by the design of the original data collection system. For confidentiality reasons, we are unable to share the data entry templates but instead will briefly explain their nature, provenance and contents. Case workers enter into the database information about each service user at the point of starting work with him/her. They derive this information from various sources including their own assessment of a child, discussions with the child, their parents, carers or various practitioners (police, teachers, social workers etc.) and written notes from formal records (e.g. safeguarding meetings). Case workers can then revisit these individual-level records and make additions or changes should new information emerge. In fact, two distinct types of records exist for CSE cases. The first (referred to here as the core record) is used across the board and covers various fundamental aspects about the service user and the support provided (e.g., age, gender, date of referral). The second (here, the additional record) comes from an extra (CSE-specific) form that is used only by certain services. It contains additional fields - selected based on theoretical and experiential knowledge as especially relevant to CSE cases - such as a service-users' youth offending history and their peers' involvement in exploitation. As the same unique identifier is used in completing both forms we were able to match cases. 
Data from these additional records were supplied for 2,951 cases ( $33 \%$ of the overall study sample): $36.2 \%(n=2,198)$ of the females and $25.2 \%(n=753)$ of the males in the sample. This difference was significant, $\left.\chi^{2}(1, n=9,042)=111.61, p<.001, V=0.11\right)$, but not meaningful as it simply reflects variation between services in the gender composition of those they support. The use of the additional record is not a function of systematic differences between services or individual cases but simply stems from local variation in data-recording practices - some services use this extra form, others do not. We cannot be certain that the sub-sample for which the extra records were available is representative of the Barnardo's CSE service-user population at large. We decided to include the variables from the additional records in the analysis nonetheless because they provided valuable information about factors that have rarely been accessible to researchers at this scale and might help stimulate further targeted research.

The two sets of records together covered a diverse range of variables, including characteristics relating to service users personal and demographic traits, the exploitation process and official responses. We excluded certain variables for reasons including low completion rates, duplication/overlap with other variables and lack of relevance to an academic study. Others we combined in order to generate information of greater relevance to the research. The final set of variables included in the study and the particular source (core or additional records) from which they originated are shown in Table 2.

Table 2 here 


\section{Research questions}

Rather than formulating a single hypothesis, or set of hypotheses, we deliberately framed our research question in broad and inclusive terms:

What are the differences and commonalities between the recorded characteristics of males and females affected by CSE and supported by Barnardo's services in the UK?

There were several reasons behind our choice of a more open, exploratory approach. Theoretical and empirical evidence (and common anecdotal claims) gave us reason to believe that boys and girls affected by CSE might differ on some fundamental dimensions (e.g., Brayley, Cockbain \& Gibson, 2014; Cashmore and Shackel, 2014; Finkelhor, 1994; Lillywhite and Skidmore, 2006; Priebe and Svedin, 2009). Consequently, we fully expected to find some associations between gender and both the individual characteristics of the children affected by CSE and official responses to their involvement in exploitation. There was, however, substantial variation between the different variables in our dataset in terms of the volume, relevance and quality of evidence available to inform any hypotheses about the relationship they might have to gender.

Given the incoherent, patchy and inconclusive nature of the existing research-base around boys and sexual abuse (Brayley, Cockbain \& Gibson, 2014; Cashmore and Shackel, 2014), we felt it inappropriate to frame the study around a formal hypothesis. While a hypothesis-driven approach might have been feasible for some of the comparatively better documented variables in our dataset, it could have meant the exclusion of other interesting and potentially informative areas that had little precedent in the research literature. A final consideration is that we used a pre-existing dataset. While the secondary data were both extensive and previously untapped as a research 
resource, the fact they had been collected prior to and independently of the research design meant we were limited in terms of what questions we could set and test empirically.

Our broad exploratory approach has its limitations. From a practical perspective, however, it is worth capitalising on a rare opportunity to expand the foundations of a poorly-researched field. While exploratory approaches rarely provide conclusive answers, the insights they generate are surely superior to those gained (or lost) by research inactivity or reliance on untested popular wisdom. Such is especially the case when dealing with a notoriously hard-to-access research population such as children affected by CSE: an issue around which the demand for research evidence to inform policy and practice far outstrips what little is available.

Despite the breadth of the research question, we had some expectations about the anticipated relationships between the gender and the various independent variables. We will now briefly set out these expectations and the grounds behind them for each independent variable in turn.

\section{Age at referral}

As highlighted by Brayley, Cockbain and Gibson (2014), there has been little in the way of large-scale analysis into the characteristics of CSE-affected children in which results are disaggregated by gender. Looking at child sexual abuse in general, however, there was reason to believe gender might be significantly associated with differences in age. More specifically, there was some evidence to suggest that the male service users might be younger on average than their female counterparts. An important (albeit now somewhat dated) epidemiological study in Philadelphia demonstrated marked differences in the age distribution of male and female victims of child sexual abuse (De Jong, Hervada \& Emmett, 1983). The distribution for girls $(n=463)$ was bimodal with peaks at six and 15 years whereas for boys $(n=103)$ the distribution had a single peak at seven years. 


\section{Ethnicity}

It has been suggested that sexual exploitation of black and minority ethnicity (BME) children is particularly underrepresented in official records on CSE (Home Affairs Select Committee 2013; OCCE 2012; Smeaton 2013). We found, however, little more in the way of theoretical, empirical or even anecdotal reason to expect a significant relationship between gender and ethnicity.

\section{Disability}

There was reason to believe that the rates of disability (physical, cognitive and/or emotional/behavioural) might be higher for males than females in our sample - as well as exceeding the national prevalence rate. The past two decades have seen increased interest in the possible association between disability and childhood maltreatment and abuse, including but not limited to child sexual abuse. In a major population-based epidemiological study $(n=50,278)$ in Omaha, Nebraska, Sullivan and Knutson (2000) reported maltreatment of $31 \%(n=1,012)$ of disabled children compared with just $9 \%(n=3,491)$ of non-disabled children. No disaggregated results were presented for males and females. In a study of children examined for suspected child sexual abuse in Norwegian hospitals in the mid 1990s ( $n=1293)$, Kvam (2000) found that $10 \%(n=29)$ of boys examined had disabilities compared with $5 \%(n=54)$ of girls. Moreover, the proportion of males in the disabled group (35\%) was shown to be higher than in the non-disabled group (22\%), indicating a particular association may exist between gender, disability and child sexual abuse.

\section{Looked-after child status}

While looked-after children have been highlighted as a high-risk group for involvement in CSE (e.g. CEOP, 2011; OCCE, 2012), we could find no prior work that examined the association with children's 
gender. Considered from another angle, a small but significant association with gender might ensue in our study simply by merit of the fact that the figures from the past five years have routinely showed around 55\% of the looked-after population in England to be male (DfE, 2014).

\section{Youth offending history (including involvement in gun/knife crime)}

We expected to see significant differences between male and female service-users in terms of youth offending rates, with males more likely to have a history of youth offending. The reasons for this were twofold. First, among the general UK population the majority of convicted young offenders are male (Ministry of Justice, 2014). Second, in a prior localised study into CSE service users in one English city, males were 1.6 times more likely than females (55\% versus $35 \%$ ) to have a criminal record (Cockbain and Brayley, 2012).

\section{Peer involvement in exploitation}

The importance of victim peer networks as a vector for CSE has only recently begun to attract research attention (e.g., Cockbain, Brayley \& Laycock, 2011; Firmin, 2013). To date, such research has focused on cases involving exploited girls and equivalent work on the role of boys' peer structures in facilitating and/or spreading abuse is lacking. We saw, however, little reason to believe that gender should be associated with significant differences in peer involvement in CSE.

\section{Service providing care (and region/nation where it was located)}

Jago and colleagues (2011) documented the extent to which areas vary in terms of the nature and quality of CSE service provisions. Detecting CSE is commonly characterised as requiring proper attention, awareness and active investment of resources (CEOP, 2011; OCCE, 2012). It would, 
therefore, seem reasonable to expect that the less well-understood phenomenon of CSE involving boys might be even more sensitive to local variations.

\section{Source of referral}

Following on from our anticipation that youth offending rates would be higher among males than females in our sample, we expected a higher proportion of boys than girls to be referred by criminal justice agencies. In line with the lack of anticipated differences in looked after rates between the genders, we did not expect significant variation between the genders in the level of social services referrals. We could find no pre-existing literature or theoretical grounds to inform any further predictions around referral source.

\section{Reason for referral}

McNaughton-Nicholls, Harvey and Paskell (2014) documented a strongly-held belief among professionals involved in CSE cases that other professionals reacted differently to the same CSE indicators/risk factors depending on whether the child in question was male or female. In males, it was suggested, such factors were more likely to be overlooked or dismissed as normal or denigrated as criminal (rather than signs of potential victimisation). Should, as the authors concluded, gendered norms and stereotypes influence responses to CSE then we should expect to find differences in referral reason for boys and girls.

\section{Methods}

Our main method was exploratory data analysis, an analytical approach pioneered by Tukey (1977). In addition, we held a focus group with frontline service managers during the analysis phase of our 
research. We used information gathered from this focus group to inform both the analytical questions considered and to contextualise the results.

The main challenge of working with the quantitative data provided was the number of missing fields: at least one field was missing from all but $2 \%$ of core records and all but $5 \%$ of additional records. Out of the ten core-data fields, in the median case six fields were missing for boys and five for girls, a significant difference, $U=6.4 \times 10^{6}, z=-23.0, p<.001$. For the additional data, in the median case five fields (out of a possible nine) were missing for boys and three for girls, again a significant difference, $U=0.6 \times 10^{6}, z=-10.2, p<.001$. A linear regression $\left(R^{2}=0.06, p<.001, F(3)=190\right)$ showed that core records for boys were significantly more likely than those for girls to have more missing fields, $B=0.23, p<.001$. The service responsible for the user was also a significant predictor of the number of missing fields $(B=0.07, p<.001)$, as was the date on which the person began to be supported by Barnardo's ( $6=-0.05, p<.001$, i.e. later records had fewer missing fields). The small co-efficient of determination $\left(R^{2}\right)$ suggests that the apparently higher number of missing fields for boys was not solely an artefact of different recording practices, either over time or between services. Barnardo's practitioners stated that caseworkers knew less about boys because referring agencies often provide less information for boys than girls and because the boys themselves tended to be less forthcoming in their disclosures.

The problem of missing data meant that we compared most variables to gender using bivariate tests only. We used non-parametric tests: the chi-square test for comparisons of categorical variables and the Mann-Whitney $U$ test for continuous variables. To estimate effect size, we calculated the Cramér's V statistic (Cramér, 1946) for categorical variables and the absolute value of $r$ (Rosenthal, 1991) for continuous variables. To aid interpretation of the results, we report the statistical tests 
along with the set of records from which each variable came (core or additional) and its completion rate in the original data provided to us.

Finally, we ran a logistic regression to determine the associations between gender (as the dependent variable) and each of the other variables in conjunction with one another. In order to maximise the number of cases included in this regression, we limited it to those variables for which there were the fewest missing values ${ }^{\text {iv }}$ : geographical location; source of referral; reason for referral; ethnicity; and looked-after status.

\section{Results}

One third of the overall sample was male $(n=2,986,33 \%)$. The proportion of males varied by year although no linear temporal trend existed - from a high of 39\% in 2010 to $24 \%$ in 2013 (see Figure 1). Perhaps more noteworthy was the large change over time in the number of referrals to Barnardo's: more than four times as many cases were dealt with in the first 10 months of 2013 than in the whole of 2008. There are many potential reasons for such variations, including changes in the capacity and funding of projects over time, the increased profile of CSE in the media and possible growth in awareness of the issue, leading to more referrals.

Figure 1 here

\section{Geographical variation}

The proportion of boys supported by each of the Barnardo's services in the sample varied substantially. For services that supported at least 100 children in the sample, the proportion that 
were boys varied between $5 \%$ and $57 \%$, with a median of $36 \%$. When service-level data were aggregated to the level of individual regions or nations ${ }^{v}$ of the UK, geographical variation remained pronounced; the proportion of male service users ranged from a low of $6 \%$ in Northern Ireland to a high of $47 \%$ in the South East of England (with an average of $28 \%$ across the individual services in the sample). Such variation should be interpreted cautiously, however, as there are many potential explanations for it other than underlying differences in the actual proportion of males and females affected by CSE in a given area. Such possible explanations include differences in staff training and awareness, the availability of male staff and the services offered in specific locations. The observed variation might also reflect the nature of CSE in a particular area, for example higher proportions of male victims might be seen in an area where the exploitation of boys tended to occur in public places (which might lead to more reporting) or where a prolific group of offenders particularly targeted boys.

\section{Source of referral}

Children were referred to Barnardo's by a variety of other agencies responsible for the care and supervision of young people, as shown in Table 3. Overall, social services were the most frequent source of referrals, followed by criminal-justice agencies such as the police, courts or probation service. There was a significant difference between males and females in the frequency with which they were referred by the different services, $\chi^{2}(6, n=8,149$ : $90 \%$ of core records $)=516.8, p<.001, V$ $=0.25$. Boys were 1.7 times more likely than girls to be referred by criminal-justice agencies and only just over half as likely as girls to be referred by social services. These differences may reflect the varying extent to which boys and girls come into contact with these agencies and/or discrepancies between sectors in the level of training and awareness around CSE and its different forms. It is perhaps noteworthy that very few referrals for either gender came from education or health agencies, even though almost all children will have had contact with professionals in those sectors. 
This may indicate a lack of awareness of CSE among those working in health or education, or procedural reasons that mean CSE concerns rarely lead to direct referrals to Barnardo's.

Table 3 here

To determine whether the gender disparity in referral agency was associated with other variables in the data, two additional tests were conducted. Contrary to our expectations, children with a criminal record were not referred significantly more often by criminal-justice agencies than those without criminal records, $\chi^{2}(1, n=1,482: 50 \%$ of additional records $)=1.8, p=.17, V=-0.04$. This finding indicated that the more frequent referral of boys by criminal-justice agencies is not solely a result of more boys being known to them (due to higher rates of youth offending among males than females). In contrast, 'looked-after' children (i.e. those under the care of the local authority) were more likely than other children to be referred by social services, $\chi^{2}(1, n=8,149$ : $90 \%$ of core records $)=226.2$, $p<.001, V=0.17$.

\section{Reason for referral}

Children were referred to Barnardo's CSE services for a variety of reasons, as shown in Table 4. There were significant differences between genders in referral reasons, $\chi^{2}(4, n=2,790$ : $95 \%$ of additional records $)=309.1, p<.001, V=0.33$. Boys were almost twice as likely as girls to be referred because of having gone missing. Going missing accounted for more than half of all referrals overall. It was not possible to explore the relationship between going missing and CSE in any more detail (because data were not available on how many children who go missing are not involved in CSE), but several other studies have highlighted a link between the two issues and further targeted research is needed (Beckett, 2011; Jago et al., 2011; Scott and Skidmore, 2006; Sharp, 2012; Smeaton, 2013). 
Table 4 here

While most boys were referred after going missing, girls were more than three times as likely as boys to be referred because of specific concerns about suspected exploitation. This result resonates with previous studies (McNaughton-Nicholls, Harvey \& Paskell, 2014; Smeaton, 2013) in which it has been suggested that practitioners are more likely to identify signs of CSE in girls than in boys. While girls were four times more likely than boys to be referred following a direct disclosure of exploitation the absolute figures for direct disclosures were very low across the sample ( $4 \%$ of cases). The rarity with which children in the sample came forward independently to say they had been exploited emphasises the importance of professionals being able to identify signs of CSE in the absence of a direct disclosure.

Age

The median age of referral to Barnardo's for boys (14 years and five months) was significantly lower than the median age for girls (14 years and nine months), $U=6.2 \times 10^{6}, z=-9.2, p<.001|r|=0.18$. Figure 2 shows that, prior to the age of 11 , more boys than girls were referred to Barnardo's. After the age of 12 , however, the number of girls was much higher than the number of boys. Once again, there are various possible explanations for this finding. It may reflect differences in the preferences of those who sexually exploit boys and girls or that boys spend time away from guardians at a younger age than girls do. Alternatively, older boys may be less susceptible than older girls to offenders' advances, or referring agencies may be less aware of the signs of CSE in teenage boys than in pre-teen boys. 
Figure 2 here

The time from the date of a child's referral to Barnardo's to when (s)he was first seen by a case worker was shorter for boys (a median wait of 97 days) than for girls (168 days). This difference was significant, $U=5.8 \times 10^{6}, z=-13.3, p<.001,|r|=0.17$. Barnardo's practitioners stated that this reflected their experiences that CSE-related concerns for boys tended to be reported at a later stage than for girls, meaning situations had often become more severe and required more immediate intervention. They said that referring agencies were more aware of vulnerability and warning signs in girls than in boys, another finding that resonated with work by McNaughton Nicholls, Harvey \& Paskell (2014). There are, however, administrative reasons why there might be a delay in beginning work with a particular child (such as lack of capacity or difficulty contacting a child), meaning that other explanations for the observed differences cannot be excluded.

\section{Ethnicity}

The distribution of service-users' ethnicities (as recorded by their case workers) was broadly in line with that of the general youth population, with no obvious under- or over-representation of any particular ethnic group (see Table 5). This runs counter to the oft-cited perception that sexual exploitation involving BME children has been overlooked relative to that involving white children (Home Affairs Select Committee 2013; OCCE 2012; Smeaton 2013). In reporting this result, the authors do not dispute that there may be particular challenges in identifying children from BME communities who are at risk of or experiencing CSE (see, e.g., Gohir, 2013; Ward and Patel, 2006).

\section{Table 5 here}


There was an apparent difference between the ethnicities of male and female service users, $\chi^{2}(4, n=$ $5,952: 66 \%$ of core records $)=12.4, p=.02, V=0.05$. It should be noted that this difference was significant only at the $p<.05$ level and that the effect size was very small; as shown in Table 5 , in no case was the gender disparity greater than $3 \%$ of all cases. Given that the present study made multiple comparisons between variables, this result may be spurious and has not therefore been treated as a significant finding in the subsequent discussion.

\section{Disability}

Male service users were significantly more likely than females to have a disability recorded on their files, $\chi^{2}(2, n=3,639: 40 \%$ of core records $)=177.1, p<.001, V=0.27$. Overall, $35 \%$ of these boys had a recorded disability, compared to $13 \%$ of these girls. The gender disparity found in our sample exceeds that of our tentative expectation based on Norwegian work by Kwam (2000). In general the overrepresentation of children with recorded disabilities corresponds to and builds upon a growing literature documenting the association between disability and increased risk of maltreatment and various forms of abuse (e.g., Sullivan and Knutson, 2000).

Figure 3 here

Figure 3 shows the disabilities recorded for service users. At least two of the three most common disabilities for both sexes - behavioural disabilities, learning disabilities and autism spectrum disorder (ASD) - were more common among the study sample than the general youth population. Emerson (2003) found that 1.4\% of girls and 3.7\% of boys in Great Britain had learning difficulties, notably lower than the figure of $6.7 \%$ of girls and $8.7 \%$ of boys in the present study. Service users also had a higher prevalence of ASD ( $1.7 \%$ of girls and $8.1 \%$ of boys) than that of $1.2 \%$ estimated for 
the general youth population (Baird et al., 2006). The ratio of boys to girls with ASD on record in the current sample (4.8:1) was slightly greater than the mean ratio of 4.3:1 found by Fombonne (2005) in a review of 37 studies of children with ASD. These differences should all be interpreted with caution, however: the present data are based on self-reporting of disabilities, while the other studies referenced here are typically based on diagnostic tests, and the Barnardo's data only record one disability per service user.

There are several potential reasons why recorded disabilities may be more common in service users than in the youth population. For example, some offenders may preferentially target disabled children because of perceived weaknesses or reduced credibility as victims. Alternatively, or additionally, certain disabilities (e.g. cognitive or behavioural ones) may impair children's abilities to evaluate risk which could in turn lead to greater exposure to would-be offenders and/or susceptibility to their advances. Another possible, but by no means mutually exclusive, explanation for the high rates of disabilities in our data is that disabled children may simply be subject to better safeguarding than non-disabled children. According to this explanation, vulnerability to CSE would be more likely to lead to a referral for support. Further targeted work is required to investigate the relationship between CSE and disability more thoroughly.

\section{'Looked-after' children}

Eighteen percent of the service users were 'looked-after children', a definition that includes those living in children's homes, secure units and foster care as well as those living at home with their parents but under the supervision of social services. There was no significant difference between the proportion of boys and girls who were looked after, $\chi^{2}(1, n=9,042: 100 \%$ of core records $)=0.02$, $p=.90, V=0.001$. 
Around $0.6 \%$ of children in the general English ${ }^{\text {vi }}$ population are looked after (DfE, 2014). Our results indicate a substantial overrepresentation of looked-after children in the CSE service user sample compared with the population at large. In this respect, our findings correspond with previous studies that have found that CSE victims are often looked-after children (CEOP, 2011; OCCE, 2012). Nationally, looked-after children are known to suffer disproportionately to the general youth population from abuse, neglect and family dysfunction (DfE, 2014), which may increase their level of risk in relation to CSE. These findings suggest that those caring for looked-after children have a particularly important role to play in spotting the signs of exploitation. No study has yet looked in detail on a large scale at how being looked after and experiences of CSE interact. Consequently, the reasons behind the overrepresentation of looked-after children among CSE samples remain unclear. As with the high rate of children with disabilities, the preponderance of looked-after children could be explained via mechanisms such as preferential targeting by offenders, above-average vulnerability to offenders' approaches, greater exposure to offenders in the first place and/or closer monitoring by practitioners - whose statutory responsibilities to report concerns would then lead to higher levels of identification.

\section{Youth offending}

Significantly more male $(48 \%)$ than female service users $(28 \%)$ were known to have a criminal record, $\chi^{2}(1, n=1,567: 53 \%$ of additional records $)=45.6, p<.001, V=0.17$. Furthermore, $10 \%$ of male and $4 \%$ of female service users were suspected of being involved in knife or gun crime (among the $46 \%$ of cases of which this information was known). These results corresponded with our expectations due to their close parallels to findings from Cockbain and Brayley's (2012) localised study. They found that $48 \%(n=53)$ of male and $35 \%(n=158)$ of female CSE service users in an English city, Derby, had criminal records. The proportion of service users with a criminal record is much 
higher than that found in the general youth population: in $2013,1.6 \%$ of boys and $0.4 \%$ of girls aged 10-17 years in England and Wales had a criminal record ${ }^{\text {vii. }}$

There are several potential reasons for the observed overrepresentation of children with criminal records in the study sample: children may commit offences as a result of being a victim of CSE (or as part of that exploitation), children may have contact with CSE offenders because of their offending and there may be more opportunities to detect CSE victimisation among children who are under the supervision of a youth-offending team. Although we had no information about the nature of the offences for which children in our sample had criminal records, we caution against assuming these would be related necessarily or particularly to sexually harmful behaviour. To this point, Cockbain and Brayley (2012) reported that just 1\% all recorded offences for their sample were sexual, in line with the proportion for recorded youth crime in England and Wales at large.

The gender disparity in offending rates appears to be less for CSE service-users than in the general youth population. After controlling for gender imbalances in the samples at large, the ratio of males to females with a criminal record was 1.7:1 in the current sample, broadly analogous to Cockbain and Brayley's (2012) figure of 1.4:1. Among the general population in 2013, in contrast, for every girl with a criminal record there were 3.7 boys. Youth offending therefore appears to be more closely associated with CSE for girls than for boys. One possible explanation for this might lie in the fact that boys and girls vary in terms of what offences they tend to commit (Youth Justice Board, 2009). 


\section{Peer involvement in CSE}

Peer involvement in CSE was known or suspected in the cases of $31 \%$ of male and $56 \%$ of female service users, $\chi^{2}(1, n=1,323: 45 \%$ of additional records $)=47.3, p<.001, V=0.19$. This disparity may be because certain types of CSE (namely those involving solo victimisation) may be more common for boys than girls (Brayley, Cockbain \& Gibson, 2014) or that boys discuss their involvement in CSE less with their peers due to the additional stigma associated with male-on-male sex (meaning that male service users might simply be less aware of their male friends' involvement in CSE). Barnardo's practitioners suggested the difference might also result from boys being less willing than girls to discuss either their own exploitation or that of their peers. Previous studies into CSE involving groups of victims have focused on female victims (Brayley, Cockbain \& Laycock, 2011; Cockbain, Brayley \& Laycock, 2011; Firmin 2013) and so at present little is known about group exploitation of boys.

\section{Multivariate analysis}

The problem of missing data meant that we carried out the most detailed analysis of the present dataset using bivariate tests. We also ran a binary logistic regression to determine whether the results of those tests changed when controlling for the other variables and potential interactions between them. To maximise the sample size available for this analysis, we only included those variables present in more than $60 \%$ of cases. Of the original sample, $23 \%$ of cases $(n=2,080)$ had complete data for all five variables in question and could therefore be included in this element of the analysis.

Table 6 here 
Overall, the model containing the independent variables shown in Table 6 was a significant predictor of whether a service user would be male or female, $\chi^{2}(21, n=2,080)=278.2, p<.001$. The pseudo- $R^{2}$ value of 0.20 , calculated as described by Cragg and Uhler (1970), indicated that there was unexplained variation in the model. This was to be expected, since there are likely to be differences between male and female service users that could not be studied using the present data. The results of Wald tests for individual predictors generally accorded with those found in bivariate tests. The region of the UK in which a service user lived, the agency referring them and the reason for the referral were all significant predictors of whether or not the service user would be male or female; in each case bivariate tests had shown that there were significant differences between the boys and girls in each of these variables individually. Ethnicity and being a looked-after child were not significant predictors of gender and both of these were factors for which no significant gender disparity (at $p<.01$ level) was found in the bivariate tests. For those predictors that were significant, the direction of the odds of a service user being male $\left(e^{b}\right.$, Table 6$)$ were the same as would be predicted by the bivariate tests ( $e^{b}$ is not shown for the region variable to protect confidentiality). The results of the regression model therefore suggest that the results of the bivariate tests for these variables are not simply artefacts caused by differences in other variables.

\section{Discussion}

This study was designed to explore empirically and systematically the relationship between CSE and the gender of the children it affects. As we have already considered the interpretation and implications of individual results in the preceding session, here we focus on discussing the study and its findings in their entirety. One of our most striking findings is also one of the simplest: one third of our sample was male. The proportion of males was markedly higher here than in prior national studies into various forms of CSE in the UK or its constituent nations (e.g., CEOP, 2011; OCCE, 2012). Such a discrepancy may be in part a function of the broad definition of CSE applied in this study 
compared to previous ones, which focused on sub-types such as 'group and gang associated CSE'. It might seem a valid challenge to suggest that the inclusion of children at risk of CSE and those suspected of perpetrating CSE might have led to the higher proportion of males in the current sample. When this was raised in the focus group with frontline Barnardo's service providers this was not felt to be an accurate assumption. Participants in the focus group expressed the strong conviction that the majority of boys they had supported were victims, even more so than with the girls. Whatever the reason for the high proportion of males in this study, the very fact that nearly 3,000 boys were supported by Barnardo's for CSE emphasises the importance of better incorporating boys and their needs into research, policy and practice.

The other findings, taken as a whole, indicate that the relationship between CSE and service users' gender is both complex and nuanced. No significant differences (at $p<.01$ level) were observed between the boys and girls in terms of ethnicity or whether or not a child was looked after. Additionally, no clear trend was observed in terms of the proportion of service users that was male per year over the core study period 2008 to 2013 inclusive ${ }^{\text {viii }}$. The substantial (and significant) variations between individual projects and regions/nations in terms of the proportion of male service users, while interesting, should be treated cautiously for reasons previously explained (e.g., differences in specialist service provision and other agencies' awareness that CSE can affect boys). In contrast, such external factors alone would inadequately explain the observed differences for the other statistically significant variations between the male and female samples. To recap, the males in the sample were, in comparison to the females: more likely to be referred by certain agencies (in particular criminal justice agencies) and less likely to be referred by others (in particular social services); more likely to be referred because of concerns related to going missing; several months younger on average; more likely to have recorded disabilities; more likely to have criminal records; and less likely to have peers also thought to be affected by CSE. 
Many of our findings resonate with previous research in which associations have been documented qualitatively and to a lesser extent quantitatively between CSE and youth offending, going missing and being in care (e.g., Beckett, 2011; Brayley and Cockbain, 2012; CEOP, 2011; Clutton and Coles, 2007; Jago et al., 2011; OCCE, 2012; Pearce, Williams \& Galvin, 2003; Scott and Skidmore, 2006). In what appears to be an isolated example of prior research covering CSE referral pathways in the UK, McNaughton-Nicholls, Harvey \& Paskell (2014) reported that practitioners dealing with CSE perceived boys to be seen by various agencies as less vulnerable than girls. Such differences in perception of gender and risk might help account for the differences in referral agencies and referral reasons documented in the current study, although this is clearly an area in need of greater attention. Even less well documented in the existing research literature is the relationship between disability, gender and CSE. Future investigation into this topic might do well to factor in gender as a consideration, given the substantial and significant differences in disability rates between boys and girls in the current study's sample.

In considering the strengths and weaknesses of this study, several factors distinguish it from most prior enquiries into CSE, both in the UK and internationally. First is the use of the quantitative approach. Although fairly common in the better-developed literature on child sexual abuse more broadly, quantitative methods have rarely been applied to the study of CSE in particular. Instead the CSE literature has been dominated by qualitative studies, with notable exceptions including evaluations of policy and its implementation (e.g., Jago et al., 2011) and small-scale studies into certain types of CSE (e.g., Cockbain, Brayley \& Laycock, 2011). The quantitative approach employed here helps to develop further the evidence base by moving towards the identification of more general - and possibly generalisable - patterns based on extensive data from numerous cases. The second distinguishing factor is the large size of the sample: 9,042 unique cases. The prevailing tendency towards small samples even in quantitative studies of CSE may be at least partially due to 
difficulties in accessing data on this sensitive and hidden (or simply overlooked) issue. In the current study, the large sample size reduces the risk of sampling error and promotes confidence in the results. The third key strength is that the data were individual-level, which permitted types of analysis not used even in large national scoping studies into CSE to date (e.g., CEOP, 2011; OCCE, 2012). Individual-level data were a critical prerequisite for us to be able to compare male and female service-user groups systematically across a wide range of independent variables and to examine possible interactions between these independent variables. The use of inferential statistics to test for the significance of the observed variations by gender and to test for possible confounding variables promotes greater confidence in the validity of our results. Other strengths worth briefly summarising include: the current nature of the data (the vast majority of case came from the period 2008-2013 inclusive); the coverage of three nations (England, Northern Ireland and Scotland); the broad range of study variables; and the unobtrusive approach to data collection.

Of course, the study also has limitations that should be considered in its interpretation and application. The ethical benefits of relying on a pre-existing sample when investigating a sensitive topic are counterbalanced by the downside to using a dataset designed primarily for administrative rather than research purposes. The categorisation of variables meant it was not always easy to find appropriate and directly comparable baseline data against which to assess the findings in a meaningful fashion. Additionally, certain variables of clear theoretical and practical interest (such as exploiters' age and gender, the nature and context of any abuse suffered and factors promoting resilience) were unavailable for inclusion in the study because they had not been collected. As previously stated, there was no way of distinguishing whether a given child had been exploited, exploited others and/or was at risk of experiencing/perpetrating CSE. Instead, all these permutations were captured under the broad tag 'affected by CSE'. Missing data was another problem, which limited the number of variables and proportion of cases that we could include in the multivariate 
analysis. More sophisticated analyses were not possible and the denominator for the various bivariate analyses depended on the number of cases for which a given variable had been completed. While it is understandable that frontline service providers might not see data entry as a key concern, hopefully studies like this can help demonstrate the value of detailed and comprehensive record keeping. Perhaps the most obvious limitation of the study, however, is the issue of external validity. The data derived from one organisation only, albeit one that is the UK's biggest provider of CSE services. Barnardo's has a broad geographical reach in its services but the cases covered here are clustered around service locations rather than being evenly distributed across the UK's nations. Linked to the issue of external validity is the perennial question of much social research of whether and to what extent - identified cases (the study sample) differ systematically from all those unidentified cases that make up the 'dark figure' of crime.

Given the complex set of processes likely to be at play in mediating children's exposure, vulnerability and resilience to sexual exploitation, it would be useful in future to consider population-based studies into CSE. The inclusion of both victims and non-victims in such studies might help disentangle potentially interrelated variables (e.g., youth offending and going missing) and enable the identification of those variables with the maximum predictive utility. The identification of empirically substantiated risk factors (and resilience factors) could support more effective and targeted deployment of ever dwindling resources (e.g., via the creation of predictive risk maps of the type used by epidemiologists). Additionally, the careful and deliberate collection of temporally-ordered data (including but not limited to the type used in longitudinal studies) could be beneficial in moving beyond identifying significant correlations towards investigating processes of cause and effect ${ }^{\mathrm{ix}}$. At present, many of the factors routinely referred to as 'risk factors' for or 'indicators' of CSE are in fact only known to be correlates. 


\section{Conclusion}

CSE is increasingly recognised at national and international levels as a crime reduction and child protection priority. Yet, the demand for robust research to inform evidence-based responses continues to outpace the still fragmented research literature on CSE. Among the most pronounced and frequently-cited gaps in the literature is the sexual exploitation of boys and young men. Consequently, this study's systematic large-scale exploration of the relationship between gender and CSE in the UK represents a novel and timely addition to the research base. Our research drew upon a rich and previously untapped resource and the study sample (9,042 cases) was unusually large for the research field. Following the approach of exploratory data analysis, we made use of individuallevel data across a wide range of variables to undertake both descriptive and inferential statistical analyses. The results demonstrate statistically significant differences by gender across a range of variables and crosscutting commonalities across others. Taken as a whole, the findings highlight the complexity of CSE; a child's gender seems to be an important factor to consider but it must be seen as just one piece of the proverbial puzzle. It is also important to note the clear overlaps between CSE and other serious social concerns such as youth offending and missing children. Given the limitations of the data, the results of this exploratory study should not be overstated. More work is needed to disentangle further the complex relationship between CSE and gender. Nonetheless, the findings indicate the dangers of continuing to ignore and overlook boys when it comes to tackling CSE. The observed differences between the male and female groups here give us reason to believe that current female-centric approaches to policy-making, victim identification and service-provision may not be serving boys adequately. In future, gender might usefully be factored into the design and delivery of research, policy and practice. 


\section{Tables}

Table 1: Cases excluded to ensure data represented only sexually exploited children

\begin{tabular}{llr}
\hline $\begin{array}{l}\text { Inclusion criteria (applied } \\
\text { sequentially in the order listed } \\
\text { here) }\end{array}$ & Reason & $\begin{array}{r}\text { Number of } \\
\text { cases excluded }\end{array}$ \\
\hline No apparent data-entry mistake & $\begin{array}{l}\text { To remove cases where values indicated } \\
\text { a human error in entering the data }\end{array}$ & 190 \\
Age recorded & $\begin{array}{l}\text { To allow filtering based on age } \\
\text { Individual aged 17 years or } \\
\text { younger when Barnardo's began } \\
\text { supporting them }\end{array}$ & $\begin{array}{l}\text { To exclude sexually exploited adults } \\
\text { erroneously recorded as CSE cases }\end{array}$ \\
$\begin{array}{l}\text { Individual aged 8 years or over } \\
\text { when Barnardo's began supporting } \\
\text { them }\end{array}$ & $\begin{array}{l}\text { To exclude very young children recorded } \\
\text { on the database because they are the } \\
\text { children of exploited adults }\end{array}$ & 960 \\
Gender recorded & To allow comparison of boys and girls & 351 \\
\hline & \multicolumn{1}{c}{ Total excluded cases } \\
\hline
\end{tabular}

Table 2: Independent variables

\begin{tabular}{lll}
\hline Variable related to ... & Core records & Additional records \\
\hline Child & $\begin{array}{l}\text { Age at referral } \\
\text { Ethnicity } \\
\text { Disability } \\
\text { Looked-after child status }\end{array}$ & $\begin{array}{l}\text { Youth offending history } \\
\text { Involvement in gun or knife crime }\end{array}$ \\
$\begin{array}{ll}\text { Exploitation process } \\
\text { Official responses }\end{array}$ & $\begin{array}{l}\text { Service providing care } \\
\text { Region/nation where service } \\
\text { located } \\
\text { Source of referral } \\
\text { Waiting time }\end{array}$ & $\begin{array}{l}\text { Peer involvement in exploitation } \\
\text { Reason for referral }\end{array}$ \\
& & \\
\hline
\end{tabular}

Table 3: Frequency of referrals from different agencies

\begin{tabular}{lrrr}
\hline & Females (\%) & Males (\%) & Both (\%) \\
\hline Social services & 41 & 24 & 35 \\
Criminal justice & 32 & 55 & 40 \\
Education & 6 & 2 & 5 \\
Health & 2 & 1 & 1 \\
Other & 19 & 19 & 19 \\
\hline
\end{tabular}


Table 4: Frequency of referrals for different reasons

\begin{tabular}{lrrr}
\hline & Females (\%) & Males (\%) & Both (\%) \\
\hline Going missing & 42 & 80 & 51 \\
Suspected exploitation & 25 & 7 & 21 \\
Concerns about relationship with adult & 14 & 4 & 12 \\
Disclosure of exploitation & 5 & 1 & 4 \\
Other & 15 & 9 & 13 \\
\hline
\end{tabular}

Table 5: Ethnicity of service users

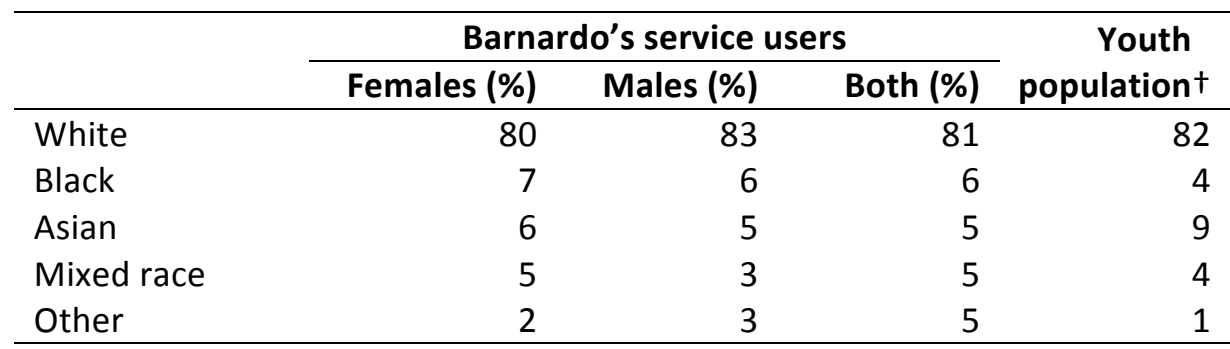

† Due to differences in publication of census data, these proportions are for peopled aged 8-17 years in England and 10-17 years in Scotland.

Table 6: Logistic regression results

\begin{tabular}{lrrrr}
\hline & Wald $\chi^{2}$ & df & $\boldsymbol{p}$ & $\boldsymbol{e}^{\boldsymbol{B}}$ \\
\hline Region of the UK & 16.5 & 8 & .036 & \\
Source of referral & 19.5 & 4 & .001 & \\
$\quad$ social services & & & & 0.69 \\
$\quad$ criminal justice & & & & 1.20 \\
$\quad$ education & & & & 0.46 \\
$\quad$ health & & & & 0.74 \\
$\quad$ Referral reason & 71.8 & 4 & $<0.001$ & \\
$\quad$ going missing & & & & 1.70 \\
$\quad$ suspected exploitation & & & & 0.47 \\
$\quad$ concerns about relationship & & & & 0.34 \\
$\quad$ with older person & & & & \\
$\quad$ disclosure of exploitation & & & & 0.36 \\
Ethnicity & 7.32 & 4 & .120 & \\
Looked-after child & 3.5 & 1 & .060 & \\
\hline
\end{tabular}


Figures

Figure 1: Number of children with whom Barnardo's began work, by year

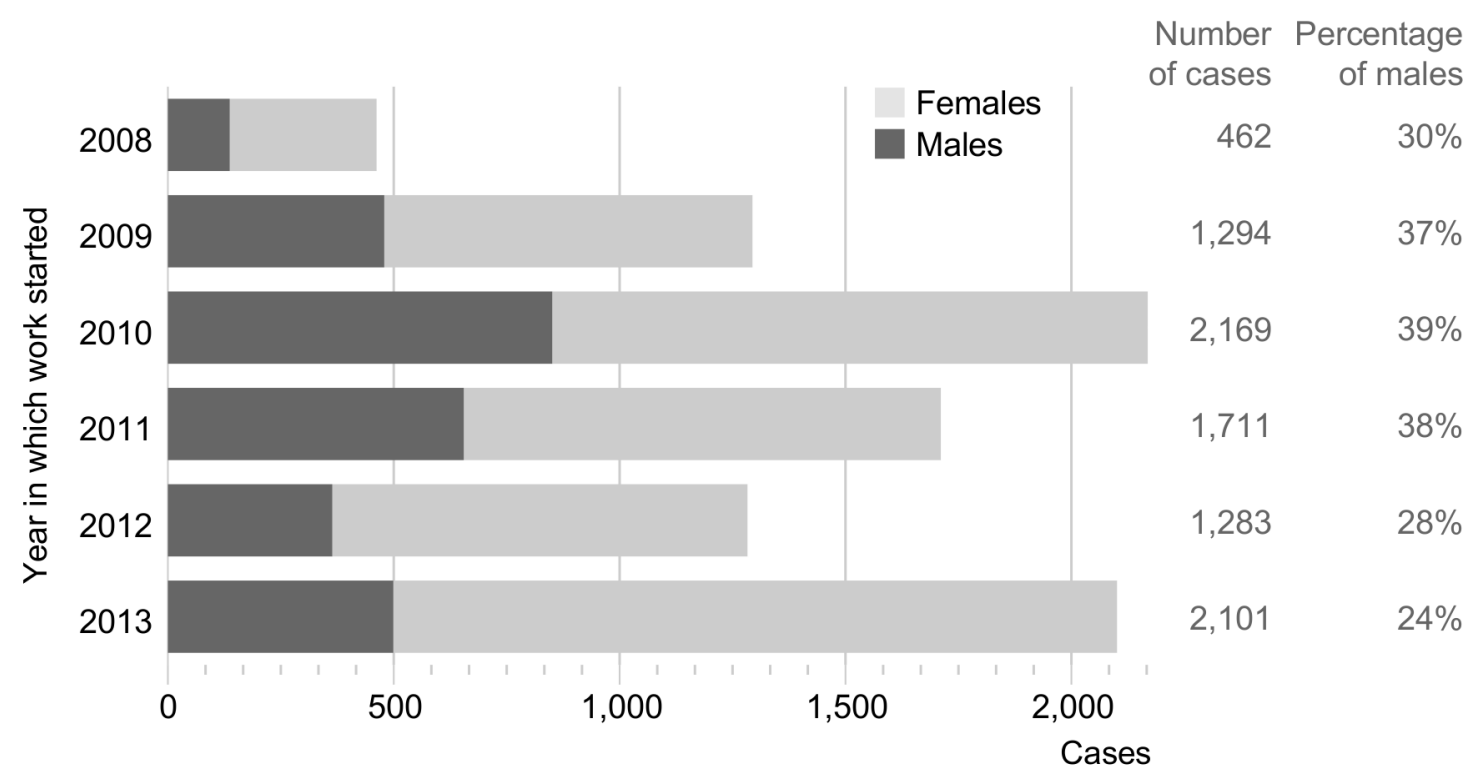

Figure 2: Age of child at referral to Barnardo's

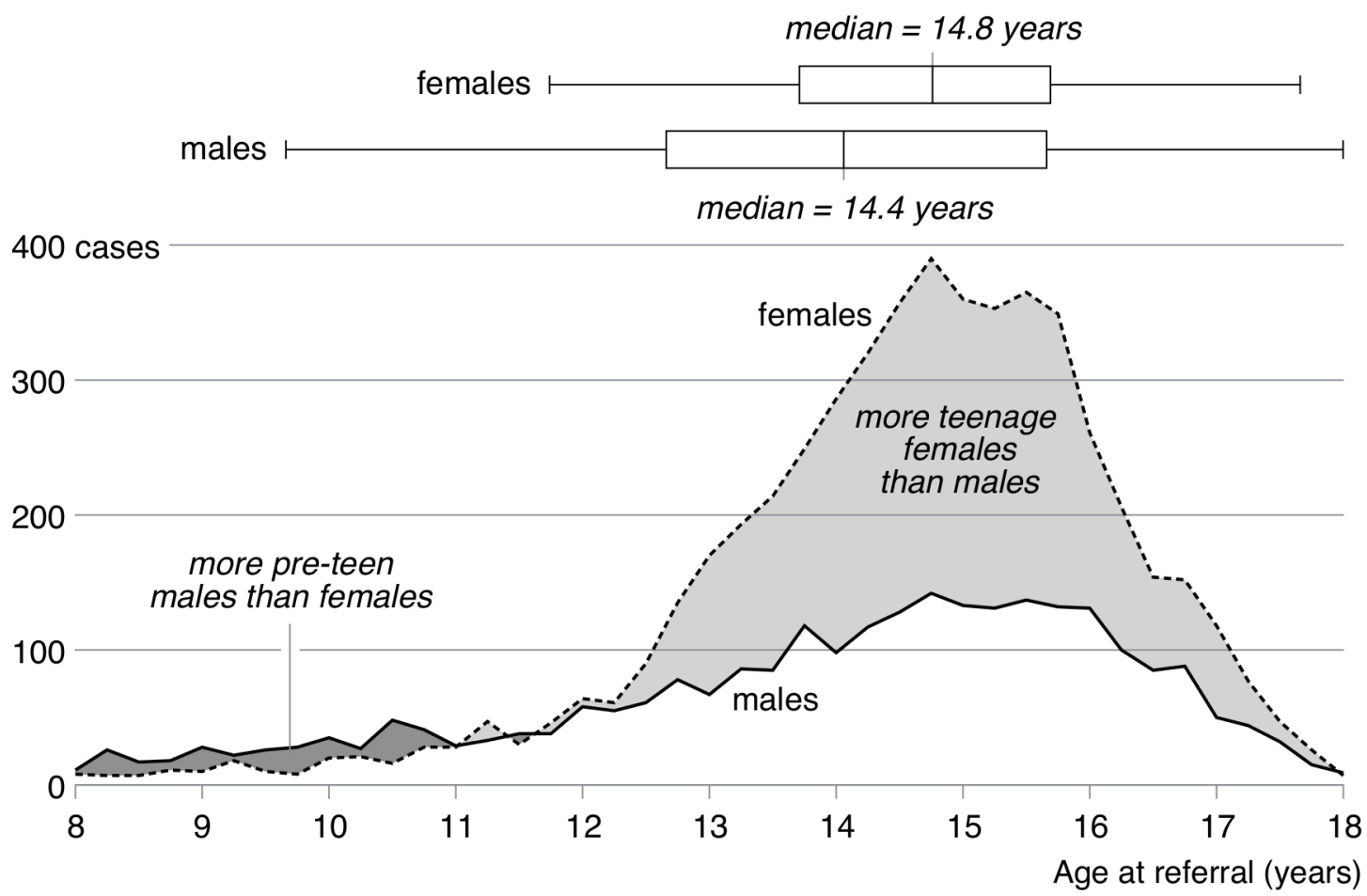


Figure 3: Disabilities recorded for service users

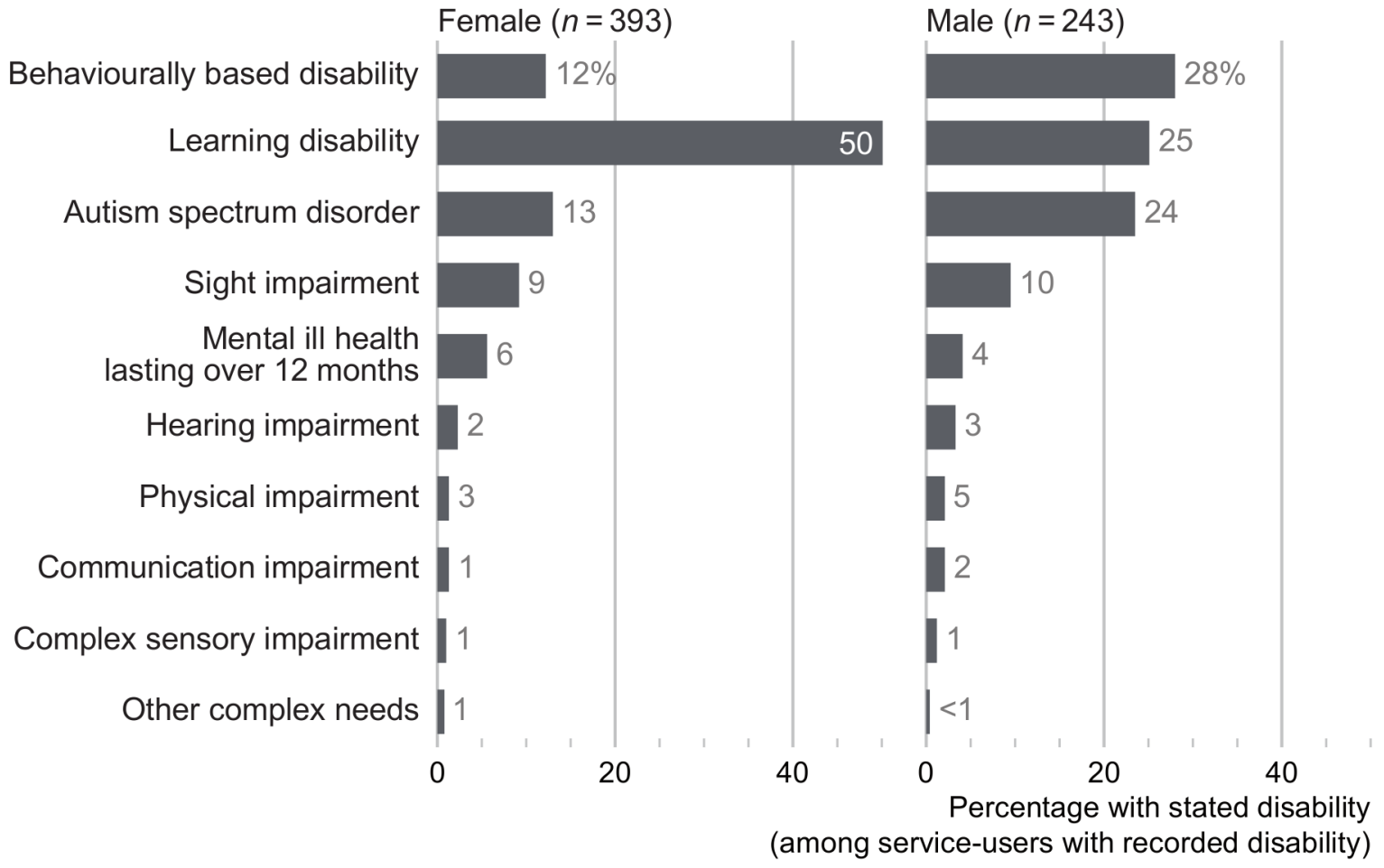




\section{References}

ACPO (Association of Chief Police Officers) (2012). ACPO child sexual exploitation action plan. London: ACPO Child Protection and Abuse Investigation Working Group. Retrieved from: http://www.ceop.police.uk/Documents/ACPOCSEPlanNPM.pdf

Alaggia, R. (2005). Disclosing the trauma of child sexual abuse: A gender analysis. Journal of Loss and Trauma, 10(5), 453-470. doi: 10.1080/15325020500193895

Appleton, J. (2014). Child Sexual Exploitation, Victimisation and Vulnerability. Child Abuse Review, 23(3), 155-158. doi: 10.1002/car.2336

Baird, G., Simonoff, E., Pickles, A., Chandler, S., Loucas, T., Medlrum, D. \& Charman T. (2006). Prevalence of disorders of the autism spectrum in a population cohort of children in South Thames: the Special Needs Autism Project (SNAP). The Lancet, 378(9531), 210-215. doi: 10.1016/S01406736(06)69041-7

Barnardo's. (2012). Cutting them free: How is the UK progressing in protecting its children from sexual exploitation? London: Barnardo's.

Barrett, D. \& Melrose, M. (2003). Courting controversy - children sexually abused through prostitution - are they everybody's distant relative but nobody's children? Child and Family Law Quarterly, 15(4), 371-382.

Beckett, H. (2011). Not a world away: the sexual exploitation of children and young people in Northern Ireland. Belfast: Barnardo's Ireland.

Brayley, H. \& Cockbain, E. (2014). British children can be trafficked too: Towards an inclusive definition of internal child sex trafficking. Child Abuse Review, 23(3), 171-184. doi: 10.1002/car.2307 Brayley, H., Cockbain, E. \& Gibson, K. (2014). Rapid evidence assessment: the sexual exploitation of boys and young men. London: Barnardo's. 
Brayley, H., Cockbain, E. \& Laycock, G. (2011). The value of crime scripting: deconstructing internal child sex trafficking. Policing: A Journal of Policy and Practice, 5(2), 132-143. doi:

10.1093/police/par024

Cashmore, J. \& Shackel, R. (2014). Gender Differences in the Context and Consequences of Child Sexual Abuse, Current Issues in Criminal Justice, 24(1), 75-104.

CEOP (Child Exploitation and Online Protection Centre) (2011). Out of mind, out of sight: breaking down the barriers to understanding child sexual exploitation. London: CEOP.

Chase, E. \& Statham, J. (2005). Commercial and Sexual Exploitation of Children and Young People in the UK - A Review. Child Abuse Review, 14(1), 4-25. Doi: 10.1002/car.881

Clutton, S. \& Coles, J. (2007). Sexual exploitation risk assessment framework. A pilot study. Cardiff: Barnardo's Cymru.

Cockbain, E. (2013). Grooming and the 'Asian sex gang predator': the construction of a racial crime threat. Race and Class, 54(2), 22-32. doi: 10.1177/0306396813475983

Cockbain, E \& Brayley, H. (2012). Child sexual exploitation and youth offending: a research note. European Journal of Criminology, 9(6), 689-700. doi: 10.1177/1477370812453401

Cockbain, E, Brayley, H. \& Laycock. G. (2011). Exploring internal child sex trafficking using social network analysis. Policing: a journal of policy and practice, 5(2), 144-157. doi:

10.1093/police/par025

CPS (Crown Prosecution Service) (2013). Interim Guidance on Prosecuting Cases of Child Sexual Abuse. London: CPS.

Cragg, J. G. \& Uhler, R. S. (1970). The demand for automobiles. Canadian Journal of Economics, 3(3), 386-406. doi: 10.2307/133656

Cramér, H. (1946). Mathematical methods of statistics. Princeton, NJ: Princeton University Press. 
DCSF (Department for Children, Schools and Families) (2009). Safeguarding Children and Young People from Sexual Exploitation, Supplementary Guidance to Working Together to Safeguard Children, London: Home Office.

De Jong, A. R., Hervada, A. R. \& Emmett, G. A. (1983). Epidemiological Variations in Childhood Sexual Abuse. Child Abuse and Neglect, 7(2), 155-162. doi: 10.1016/0145-2134(83)90067-4

DfE (Department for Education) (2014). Children looked after in England (including adoption and care leavers) year ending 31 March 2014. London: Office for National Statistics.

DfE. (2011). Tackling child sexual exploitation: Action plan. London: DfE.

Disch, E. \& Avery, N. (2001). Sex in the Consulting Room, the Examining Room, and the Sacristy: Survivors of Sexual Abuse by Professionals, American Journal of Orthopsychiatry, 71(2), 214-217. doi: 10.1037/0002-9432.71.2.204

Edelson, M. (2012). Why Have All the Boys Gone? Gender Differences in Prosecution Acceptance of Child Sexual Abuse Cases, Sexual Abuse: A Journal of Research and Treatment, 25(5), 461-481. doi: $10.1177 / 1079063212465900$

Emerson, E. (2003). Prevalence of psychiatric disorders in children and adolescents with and without intellectual disability. Journal of Intellectual Disability Research, 47(1), 51-58. doi: 10.1046/j.13652788.2003.00464.x

Feiring, C., Taska, L. \& Lewis, M. (1999) Age and gender differences in children's and adolescents' adaptation to sexual abuse, Child Abuse \& Neglect, 23(2), 115-128. doi: 10.1016/S01452134(98)00116-1

Finkelhor, D. (1994). The international epidemiology of child sexual abuse. Child Abuse and Neglect, 18(5), 409-417. doi:10.1016/0145-2134(94)90026-4

Finkelhor, D. (1986). A source book on child sexual abuse. Newbury Park, CA: Sage. 
Firmin, C. (2013). Busting the 'gang-rape' myth: Girls' victimisation and agency in gang-associated sexual violence. In M. Horvath and J. Woodhams (Eds.), Handbook on the study of multiple perpetrator rape (pp 97-115). Abingdon: Routledge.

Fombonne, E. (2005). The changing epidemiology of autism. Journal of Applied Research in Intellectual Disabilities, 18(4), 281-294. doi: 10.1111/j.1468-3148.2005.00266.x

Forrest, S. (2007), Boys, Young Men and Sexual Health Services: A Summary of a Review of the Academic Literature. London: Brook.

Gohir, S. (2013). Unheard voices: the sexual exploitation of Asian girls and young women. Birmingham: Muslim Women's Network UK.

Grayston, A. \& De Luca, R. (1999). Female Perpetrators of Child Sexual Abuse: A Review of the Clinical and Empirical Literature. Aggression and Violent Behavior, 4(1), 93-106. doi: 10.1016/S13591789(98)00014-7

Harvey, J., Hornsby, R. \& Sattar, Z. (2015). Disjointed Service: An English Case Study of Multi-Agency Provision in Tackling Child Trafficking. British Journal of Criminology, 55(3), 494-513. doi: $10.1093 / \mathrm{bjc} / \mathrm{azu} 115$

Home Affairs Select Committee (2013). Child sexual exploitation and the response to localised grooming: second report of session 2013-14. London: The Stationery Office.

Home Office (2015). Tackling child sexual exploitation. London: The Stationery Office. Home Office (2011). UK action plan on tackling child sexual exploitation. London: The Stationery Office.

Homma, Y., Wang, N., Saewyc, E. \& Kishor, N. (2012). The Relationship Between Sexual Abuse and Risky Sexual Behavior Among Adolescent Boys: A Meta-Analysis, Journal of Adolescent Health, 51(1), 18-24. doi: 10.1016/j.jadohealth.2011.12.032 
Jago, S., Arocha, L., Brodie, I., Melrose, M., Pearce, J. \& Warrington, C. (2011). What's going on to safeguard children and young people from sexual exploitation? How local partnerships respond to child sexual exploitation. Luton: University of Bedfordshire.

Jago, S. \& Pearce, J. (2008). Gathering evidence of sexual exploitation of children and young people: A scoping exercise. Luton: University of Bedfordshire.

Jay, A. (2014). Independent Inquiry into Child Sexual Exploitation in Rotherham 1997-2013. Retrieved from: www.rotherham.gov.uk/downloads/file/1407/independent_inquiry_cse_in_rotherham John Jay College of Criminal Justice (2006). The Nature and Scope of Sexual Abuse of Minors by Catholic Priests and Deacons in the United States, 1950-2002. Washington, D.C.: United States Conference of Catholic Bishops.

Kvam, M. (2000). Is sexual abuse of children with disabilities disclosed? A retrospective analysis of child disability and the likelihood of sexual abuse among those attending Norwegian hospitals. Child Abuse \& Neglect, 24(8), 1073-1084. doi: 10.1016/S0145-2134(00)00159-9

Lillywhite, R. and Skidmore, P. (2006). Boys Are Not Sexually Exploited? A Challenge to Practitioners, Child Abuse Review, 15(5), 351-361. doi: 10.1002/car.952

Lowe, K. \& Pearce, J. (2006). Young people and sexual exploitation. Child Abuse Review, 15(5), 289293. doi: $10.1002 /$ car.958

McNaughton-Nicholls, C, Harvey, S. \& Paskell, C. (2014). Sexual exploitation of boys and young men: interviews with professionals. London: Barnardo's.

Moody, C. (1999) Male child sexual abuse, Journal of Pediatric Health Care, 13(3), 112-119. doi: $10.1016 / 50891-5245(99) 90072-X$ Ministry of Justice (2014). Youth justice annual statistics: 2012 to 2013. London: Ministry of Justice. 
National Statistics (2014). Population Estimates for UK, England and Wales, Scotland and Northern Ireland, Mid-2013. London: Office for National Statistics.

Nelson, A. \& Oliver, P. (1998). Gender and the construction of consent in child-adult sexual contact beyond gender neutrality and male monopoly. Gender and Society, 12(5), 554-577.

doi: $10.1177 / 089124398012005004$

OCCE (Office of the Children's Commissioner for England) (2012). 'I thought I was the only one. The only one in the world.' The Office of the Children's Commissioner's inquiry into child sexual exploitation in gangs and groups, interim report. London: OCCE.

Palmer, T. (2001). No son of mine! Children abused through prostitution. London: Barnardo's.

Paolucci, E., Genuis, M. \& Violato, C. (2010). A Meta-Analysis of the Published Research on the Effects of Child Sexual Abuse, The Journal of Psychology: Interdisciplinary and Applied, 135(1), 17-36. doi: $10.1080 / 00223980109603677$

Parkinson, P., Oates, K. \& Jayakody, A. (2001). Breaking the Long Silence: Reports of Child Sexual Abuse in the Anglican Church of Australia, Ecclesiology, 6(2), 183-200. doi:

$10.1163 / 174413610 \times 493791$

Pearce, J., Williams, M. \& Galvin, C. (2003). It's someone taking a part of you: A study of young women and sexual exploitation. London: National Children's Bureau.

Priebe, G. and Svedin, C. (2009). Prevalence, Characteristics and Associations of Sexual Abuse with Sociodemographics and Consensual Sex in a Population-Based Sample of Swedish Adolescents, Journal of Child Sexual Abuse, 18(1), 19-39. doi: 10.1080/10538710802584635

Public Petitions Committee. (2014). Inquiry into tackling child sexual exploitation in Scotland. Edinburgh: Public Petitions Committee. 
Radford, L., Corral, S., Bradley, C., Fisher, H., Bassett, C., Howat, N. and Collishaw, S. (2011). Child abuse and neglect in the UK today. London: NSPCC.

Rosenthal, R. (1991). Meta-analytic procedures for social research. Newbury Park, CA: Sage.

Scott, S. and Skidmore, P. (2006). Reducing the risk: Barnardo's support for sexually exploited young people - A two-year evaluation. London: Barnardo's.

Scrandis, D. \& Watt, M. (2014). Child Sexual Abuse in Boys: Implications for Primary Care, The Journal for Nurse Practitioners, 10(9), 706-713. doi: 10.1016/j.nurpra.2014.07.021

Sharp, N. (2012). Still Hidden? Going missing as an indicator of child sexual exploitation. London: Missing People.

Smallbone, S. \& Wortley, R. (2000). Child sexual abuse in Queensland: Offender characteristics and modus operandi. Brisbane: Queensland Crime Commission.

Smallbone, S., Marshall, W. \& Wortley, R. (2008). Preventing Child Sexual Abuse: Evidence, Policy and Practice. Cullompton: Willan

Smeaton, E. (2013). Running from hate to what you think is love: the relationship between running away and child sexual exploitation. London: Barnardo's.

Stoltenborgh, M., van ljzendoorn, M., Euser, E. \& Bakermans-Kranenburg, M. (2011). A Global Perspective on Child Sexual Abuse: Meta-Analysis of Prevalence Around the World, Child Maltreatment, 16(2), 79-101. doi: 10.1177/1077559511403920

Sullivan, P. \& Knutson, J. (2000). Maltreatment and disabilities: A population-based epidemiological study. Child Abuse \& Neglect, 24(10), 1257-1273. doi: 10.1016/S0145-2134(00)00190-3

Tukey, J. (1977). Exploratory data analysis. New York: Pearson.

Ward, J \& Patel, N. (2006). Broadening the discussion on 'sexual exploitation': ethnicity, sexual exploitation and young people. Child Abuse Review, 15(5), 341-350. doi: 10.1002/car.953 
Welsh Assembly Government (2010). Safeguarding Children and Young People from Sexual Exploitation: Supplementary Guidance to Safeguarding Children: Working Together Under the Children Act 2004. Cardiff: Welsh Assembly Government.

Youth Justice Board (2009). Girls and offending: patterns, perceptions and interventions. London: Youth Justice Board.

\footnotetext{
'A notable exception is clergy-perpetrated abuse for which male victims have been found to outnumber females (Disch and Avery, 2001; John Jay College of Criminal Justice, 2006; Parkinson, Oates \& Jayakody, 2010).

ii Barnardo's also has services in Wales but these operate on a different case management system and could therefore not be included in the study.

iii The categories are not mutually exclusive: for example, a child might have been sexually exploited themselves but also gone on to exploit their peers.

${ }^{\text {iv }}$ In a logistic regression of this nature, a missing data entry on any of the variables in the regression would disqualify the whole case from inclusion.

${ }^{v}$ As there were far fewer services in Scotland and Northern Ireland than in England, the services in these countries were aggregated to national rather than regional level to protect confidentiality.

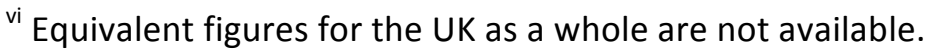

vii These proportions were calculated based on the number of boys and girls with at least one recorded caution or conviction (Ministry of Justice 2014, table 3.6) and the number of children between 10 and 17 years old in the population (National Statistics, 2014).

viii Although the earliest cases in the sample dated back to $2004,>99 \%(n=9,020)$ cases came from the period 2008-2013 inclusive.
} 
${ }^{\mathrm{ix}}$ Even well designed and executed research may not uncover linear and predictable relationships due to the inherent complexity of CSE. For example, going missing may function as a risk factor for CSE for some, a consequence of CSE for others and a simple correlate for others (see Beckett, 2011) 